\title{
O ENSINO DA HISTÓRIA LOCAL E ITINERÁRIOS DA DISCIPLINA TÓPICOS DE HISTÓRIA DA EDUCAÇÃO EM ALAGOAS: DIÁLOGOS POSSÍVEIS
}

\author{
TEACHING OF LOCAL HISTORY AND ROUTES OF COURSE TOPICS HISTORY OF \\ EDUCATION IN ALAGOAS: POSSIBLE DIALOGUE
}

\author{
Roseane Maria Amorim ${ }^{1}$ \\ Ângela Maria dos Santos ${ }^{2}$
}

\begin{abstract}
RESUMO: Este texto tem por objetivo principal registrar as experiências vividas na formação de professores e professoras articulando-as com as discussões voltadas para o debate epistemológico do conhecimento histórico escolar. Sendo assim, o presente artigo discute a importância do ensino da história local na formação de estudantes do curso de Pedagogia/CEDU/UFAL que atuam ou vão atuar nos anos iniciais do Ensino Fundamental. Optamos no primeiro momento por uma reflexão sobre o ensino de História de maneira geral entrelaçado pela discussão sobre 0 ensino de história local analisando inclusive projetos pedagógicos de Cursos de Pedagogia de algumas Universidades Federais do Brasil. No decorrer do artigo nos debruçamos sobre a experiência vivida na disciplina Tópicos de História da Educação em Alagoas.
\end{abstract}

Palavras-chave: Educação. Ensino de História. História Local.

\begin{abstract}
This paper aims to record the main experiences in teacher education, relating them to the discussions focused on the epistemological debate about school knowledge. Therefore, this article discusses the importance of the teaching local history in the formation of the undergraduates of Pedagogy / CEDU / UFAL, that already teaches in the initial years of elementary school or who still will teach. We decided, at first, by reflection on the teaching of history in general interconnected with discussion on teaching local history, also analyze some political-pedagogical projects of the Course Pedagogy of some Federal Universities of Brazil.Throughout the article, we look closely at the experience in the discipline of History Education Topics in Alagoas.
\end{abstract}

Keywords: Education. Teaching of History. Local History.

\footnotetext{
${ }^{1}$ Universidade Federal de Alagoas. Professora de Filosofia, Ensino de História Local e História da Educação

${ }^{2}$ Graduanda de pedagogia da Universidade Federal de Alagoas
} 


\section{Introdução}

Dos Pedagogos se espera que conheçam bem as teorias pedagógicas, os pressupostos teórico-metodológicos para ensinar a ler e escrever, as diversas técnicas de ensino e de pesquisa, além do domínio sobre a produção textual. Poucas vezes se tem discutido a necessidade desse profissional no domínio da história e, especialmente, da história local.

O ensino da história local tem sido negligenciado de maneira geral na formação de professores no Brasil e não é diferente no Estado de Alagoas. No máximo o projeto político pedagógico do curso de Pedagogia indica como eletiva uma disciplina que possibilite essa reflexão caso algum professor ou professora queira se aventurar por este caminho.

Assim, pensamos neste artigo fazer um exercício reflexivo de aprendizagem sobre o ensino da história local e sobre a trajetória da disciplina Tópicos de História da Educação em Alagoas, no curso de Pedagogia da Universidade Federal de Alagoas, vivenciada no primeiro semestre de 2012 no período matutino. Esperamos que esta produção possa dialogar e contribuir com aqueles e aquelas que desejam pesquisar sobre tal temática.

O que pretendemos é, em primeiro lugar, abordar de forma abrangente e ao mesmo tempo particular a história local como campo de investigação na medida em que tomamos a nossa experiência como lócus de aprendizagem e de pesquisa. Para isso estamos ancorados em diversos estudiosos como Samara e Tupy (2010) Rocha (2002) Pesavento (2003), entre outros autores.

$\mathrm{Na}$ primeira parte do artigo refletimos sobre o ensino de História e de História local na formação de professores e professoras. Realizamos também um estudo exploratório em projetos políticos pedagógicos do curso de Pedagogia de algumas Universidades Federais do Brasil e, por último, relatamos de forma breve o trabalho vivenciado em uma turma do curso de Pedagogia, trazendo algumas contribuições dos estudantes que tiveram a oportunidade de cursar a disciplina. Enfim, este texto se propõe ajudar os novos estudiosos a conhecerem um pouco sobre alguns problemas relativos a formação dos Pedagogos. 
Pretendemos, desse modo, desenvolver estudos que possibilitem a reflexão sobre a prática sem cair num praticismo vazio. Entendemos também que o ensino é o lócus da aprendizagem, da pesquisa e que possibilita a construção de perguntas que poderão favorecer novos projetos de pesquisa.

\section{O ensino da história local: algumas considerações iniciais}

Ensinar História não é uma tarefa simples como muita gente pensa, pois é uma disciplina que exige a articulação de acontecimentos em diversos tempos históricos e em contextos diferentes.

Amorim (2004) afirma que a realidade da sala de aula mostra que o ensino de História está inserido num contexto bastante complexo. Aspectos que vão desde as condições de vida dos alunos e das alunas, passando pela questão da nossa formação até a distribuição das disciplinas no currículo, influenciam o trabalho do professor e da professora da educação básica. Sabemos que as disciplinas de Matemática e Língua Portuguesa são consideradas as mais importantes para serem estudadas pelos educandos e educandas e, nessa perspectiva, como fazer para que os discentes vejam significado nesse tipo do conhecimento? Como realizar uma transposição didática eficiente, isto é, como operar a passagem do conhecimento científico para o conhecimento a ser ensinado aos alunos e às alunas de forma que estes realmente aprendam? Segundo Rocha (2002), o ensino da Matemática é parcialmente formulado pelos professores e os estudantes, que operam a partir dessas sentenças, enquanto que no ensino de história os educandos e educandas precisam elaborar juízos por inteiro, fazer conexão, seguir a lógica interna e externa do acontecimentos, enfim, internalizar as regras produzidas nas narrativas históricas.

Aprender História envolve uma série de fatores e condições que, muitas vezes, no cotidiano escolar, não se tornam muito claros para os docentes. Essas discussões nos alertam para a reflexão de que aprender História significa ter uma flexibilidade muito maior de raciocínio, exigindo dos discentes capacidades de comparação e abstração necessárias ao efetivo aprendizado. Determinados conceitos trabalhados nessa disciplina, por exemplo, são ambíguos e requerem uma discussão mais aprofundada. Pesquisadores da Espanha e de outros países, 
como Carretero (1997), vêm mostrando através das suas pesquisas que, quando estamos tratando de conceitos como revolução, monarquia e democracia, é pertinente que o aluno aprenda primeiro o significado desses conceitos na nossa sociedade, em suas diversas dimensões para depois entendê-los em outros contextos. Isso se dá pelo fato desses conceitos serem mutantes, isto é, ao longo da História adquirirem vários significados. Diante de tal complexidade, essas pesquisas nos alertam sobre a necessidade de ancorar esses conceitos trabalhados com o que os alunos já sabem, ou seja, com os conhecimentos prévios dos alunos e das alunas (AMORIM, 2004).

Seguindo esse pensamento acerca da complexidade do ensino de História, Fonseca (2004, p. 62) reporta que "os homens fazem a História e são produtores de seu próprio conhecimento histórico". De fato o homem é por natureza um ser histórico. É a partir da história que ele se constrói enquanto sujeito e transforma sua realidade.

No entanto, como um sujeito pode se sentir parte de uma história em que suas origens, seus valores, sua cultura não se enquadram dentro da História oficial ensinada nos livros didáticos? Uma história narrada somente por homens brancos, que distorce os verdadeiros acontecimentos históricos e relata apenas o que Ihes convêm. Logo, foi nesse contexto de disseminação de conceitos racistas e preconceituosos que o ensino de história permaneceu por muito tempo, e que, muitas vezes, ainda se apresente nos dias atuais. Isso advém do processo do eurocentrismo, que por sua vez influenciou bastante a história do Brasil, através da organização do currículo e programas de ensino, acarretando na fragilidade do ensino de história de muitos brasileiros.

O ensino de História torna-se algo complexo, exigindo uma dose de discussões amplas e de produções em diferentes dimensões que esclareçam as várias facetas dessa disciplina. Contudo, devemos assinalar que a História, enquanto ciência tem por natureza os homens como objeto, isto é, não se interessa pelo abstrato, eterno e imutável, mas pelas relações humanas, pelos homens e mulheres dotados de funções múltiplas, de atividades diversas, de preocupações e aptidões variadas.

Entendemos que o ensino da História local pode possibilitar ao educando e educanda uma reflexão sobre questões da realidade em que está inserido de 
forma significativa. Schmidt e Cainelli (2004) advertem, entretanto, que o trabalho com a história local precisa levar em considerações alguns aspectos tais como: a) a abrangência do uso do conceito local; b) uma realidade local para ser entendida não pode ser desvinculados de questões de âmbito internacional e nacional; a história local pode ser um indicador da construção de identidade por parte do estudante, por outro lado a identidade tem marcos relacionais que são entrelaçados com o processo de mundialização da economia. Em outras palavras, no trabalho com histórias próximas da comunidade faz-se necessário fazer a relação com contextos mais amplos, produzir inferências, estabelecer conexões e rever determinados posicionamentos.

De maneira geral as autoras supracitadas anteriormente apontam algumas possibilidades no estudo com a história local. O trabalho nessa perspectiva pode promover uma história menos homogênea, sem silenciar as multiplicidades de vozes e especificidade de determinados sujeitos históricos. Facilita a compreensão entre as permanências, rupturas, continuidade, descontinuidade e comparação de realidades diferentes. Além disso, possibilita a inserção do estudante na historicidade da sua comunidade e a valorização do patrimônio histórico da sua localidade. Em outras palavras, a história local proporciona momentos de pesquisas com fontes que estão disponíveis na própria comunidade e valoriza o conhecimento das pessoas idosas e que na nossa sociedade não são estimadas como deveriam.

Assim, o estudo da história local pode proporcionar também a construção e o uso de um banco de dados na medida em que a disciplina permite a troca de conhecimentos e levantados de informações em confronto com a realidade local e nacional proporcionando a armazenação de dados, inclusive para novos pesquisadores e pesquisadoras (SAMARA, TUPY, 2010).

Ao partir da premissa que a história diz respeito ao conjunto de experiências vividas por sujeitos encarnados, portanto, relacionadas as questões reais do dia a dia não se pode desconsiderar as lutas travadas no cotidiano. 0 ensino da história local pode favorecer a superação de mera transmissão de conhecimentos e possibilitar a consolidação da análise da realidade em que o sujeito encontra-se inserido. 
É possível ancorar as discussões da realidade local mostrando as relações com os fatos históricos mais universais. Realizar reflexões sobre as relações entre os acontecimentos permite aos educandos e educandas operar com questões que aparentemente são distintas. No dizer de Oliveira,

[...] o que se considera importante ressaltar e discutir, nesta oportunidade, é a necessidade de tornar o ensino de História objeto de problematização nos cursos de graduação, ou seja, torná-lo tema de pesquisa em um sentido amplo do termo, tanto em monografias dissertações e teses, quanto em objeto de análise em componentes curriculares vinculados ou não a períodos e temáticas históricas, cursos de extensão, ações variadas de práticas como componentes curriculares, projetos de ensino, extensão, entre outros (2009, p.120).

Nessa perspectiva o ensino da história local permite também repensar sobre as lacunas da nossa formação no tocante ao conhecimento que temos sobre a nossa realidade. Questões que precisam ser urgentemente estudadas vêem a tona mostrando determinados estereótipos construídos ao longo do tempo, como também, fica evidente o desconhecimento que temos sobre fatos da nossa região. Como exemplo dessa situação podemos mencionar a situação das comunidades remanescentes de quilombos. Não é diferente em relação a história dos indígenas e dos bairros que compõem a história da nossa cidade e do nosso Estado. Tudo isso parece que não tem a mínima importância no curso de formação de professores e professoras. E quando os nossos estudantes vão para sala de aula atuar como professores e professoras reproduzem na melhor das hipóteses apenas o que está no livro didático sem questionamento do que está posto.

A história local e do cotidiano no dizer de Paim e Correa (2009, p.28) "[...] possibilita estudos comparativos que permitem estabelecer semelhanças e diferenças." Além disso, favorece o contato com as histórias apagadas pela historiografia oficial. Sabemos que a identidade se constrói também pelo conhecimento que temos da nossa ancestralidade, das nossas histórias familiares e da comunidade ao qual pertencemos. Pesquisas como a de Paim e Correa (2009) vem evidenciar o desconhecimento dos professores das séries inicias sobre a História do Brasil e a história local especificamente. Dessa forma, 
podermos afirmar a fragilidade da formação inicial nos cursos de pedagogia sobre tais questões.

Assim como o historiador precisa dialogar com as fontes e o/a professor (a) que ensina História precisam ir a busca de traços, de pegadas e vestígios que estão no local que será objeto de estudo. Problematizar a realidade estudada, comparar com outras instâncias e ir montando o quebra-cabeça do contexto estudando és aí um grande desafio. Para isso é preciso prestar atenção as evidências do passado e fazer a relação com o presente para podermos interpretar a realidade, pois ela não é transparente (PESAVENTO, 2003).

É nesse contexto que precisamos oferecer aos novos pedagogos e pedagogas uma formação teórica sólida capaz de lhe dar suporte para que promova um ensino significativo e a partir daí possa melhorar de alguma forma a qualidade do ensino. É com esse pensamento que vamos analisar os Projetos Políticos Pedagógicos de alguns cursos de Pedagogia e como esses cursos dialogam com a história local.

\section{Os projetos políticos pedagógicos dos cursos de Pedagogia de Universidades Federais brasileiras: algumas considerações sobre o estudo da história local}

Ao analisar os Projetos Políticos Pedagógicos dos cursos de Pedagogia de algumas universidades federais do Brasil verificamos que nem sempre a história local aparece como elemento importante na formação dos futuros pedagogos/as. Com o objetivo de aprofundar as nossas discussões sobre a nossa hipótese levantada realizamos uma análise sucinta sobre tais propostas. No levantamento realizado procuramos refletir sobre o perfil dos egressos, os objetivos do curso, e se as disciplinas experenciadas ao longo do curso contemplam o ensino da história local. Para facilitar o estudo elaboramos um quadro sintetizando alguns dados que serão explicitados a seguir. 
Quadro 1 Projeto Políticos Pedagógicos dos Cursos de Pedagogia analisados $^{3}$

\begin{tabular}{|c|c|c|c|}
\hline Universidade & $\begin{array}{l}\text { Concepção, } \\
\text { Finalidades, } \\
\text { princípios e perfil } \\
\text { dos egressos. }\end{array}$ & $\begin{array}{l}\text { Objetivos e/ou } \\
\text { competência }\end{array}$ & Disciplinas \\
\hline $\begin{array}{l}\text { Federal de } \\
\text { Pernambuco }\end{array}$ & 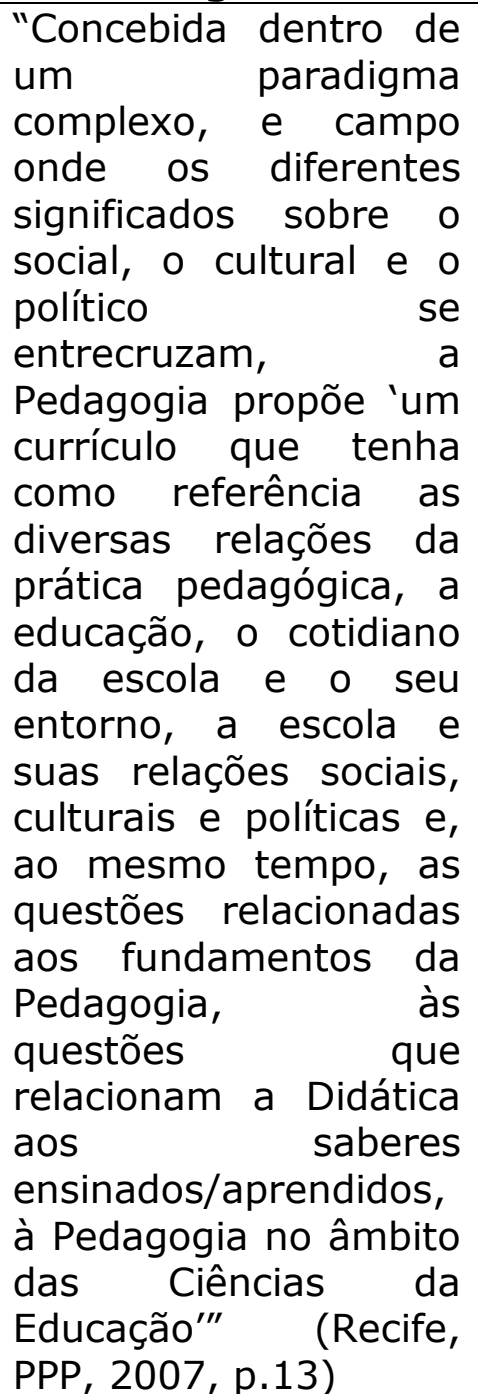 & 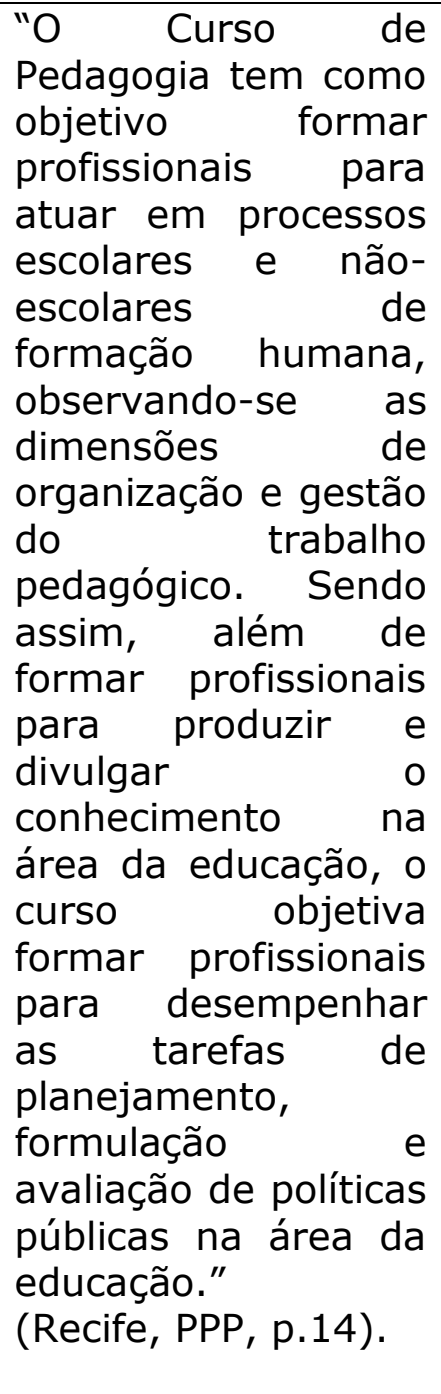 & $\begin{array}{l}\text { Aparece a } \\
\text { disciplina } \\
\text { educação no } \\
\text { Nordeste que } \\
\text { dependendo, } \\
\text { poderá ser } \\
\text { estudada por } \\
\text { um viés } \\
\text { histórico com } \\
\text { o olhar para } \\
\text { a história } \\
\text { local. }\end{array}$ \\
\hline $\begin{array}{l}\text { Universidade } \\
\text { Federal do } \\
\text { Piauí }\end{array}$ & $\begin{array}{l}\text { Situar-se no momento } \\
\text { histórico, } \\
\text { reconhecendo suas } \\
\text { potencialidades e } \\
\text { limitações, assumindo } \\
\text { compromissos éticos } \\
\text { com a valorização dos } \\
\text { profissionais da } \\
\text { educação e a defesa } \\
\text { da escola pública, bem }\end{array}$ & $\begin{array}{l}\text { "Criar, planejar, } \\
\text { realizar, gerir e } \\
\text { avaliar situações } \\
\text { didáticas eficazes } \\
\text { para a aprendizagem } \\
\text { e para o } \\
\text { desenvolvimento dos } \\
\text { alunos, utilizando o } \\
\text { conhecimento das } \\
\text { áreas ou disciplinas a }\end{array}$ & $\begin{array}{l}\text { Na listagem } \\
\text { de disciplinas } \\
\text { eletivas e } \\
\text { obrigatórias } \\
\text { não } \\
\text { apresenta } \\
\text { nenhuma } \\
\text { disciplina } \\
\text { sobre história } \\
\text { local. Isso }\end{array}$ \\
\hline
\end{tabular}

${ }^{3}$ Alertamos ao leitor que não realizamos um estudo aprofundado dos Projetos Políticos Pedagógicos do Curso de Pedagogia por fugir do objetivo deste trabalho. 


\begin{tabular}{|c|c|c|c|}
\hline & $\begin{array}{l}\text { como uma } \\
\text { educação de qualidade } \\
\text { socialmente } \\
\text { referenciada (PPP. s/d, } \\
\text { p.16). }\end{array}$ & $\begin{array}{l}\text { serem ensinadas, } \\
\text { das temáticas sociais } \\
\text { transversais ao } \\
\text { currículo escolar, dos } \\
\text { contextos sociais } \\
\text { considerados } \\
\text { relevantes para a } \\
\text { aprendizagem } \\
\text { escolar, bem como } \\
\text { as especificidades } \\
\text { didáticas envolvidas; } \\
\text { (PPP.s/p) }\end{array}$ & $\begin{array}{lr}\text { não } & \text { significa } \\
\text { que } & \text { não } \\
\text { poderá } & \text { ser } \\
\text { abordada } & \\
\text { dentro } & \text { de } \\
\text { alguma } & \text { área } \\
\text { ou } & \text { por } \\
\text { projeto } & \text { de } \\
\text { extensão } & \text { e } \\
\text { pesquisa. } & \end{array}$ \\
\hline $\begin{array}{l}\text { Universidade } \\
\text { de São Paulo } \\
\text { - USP. }\end{array}$ & 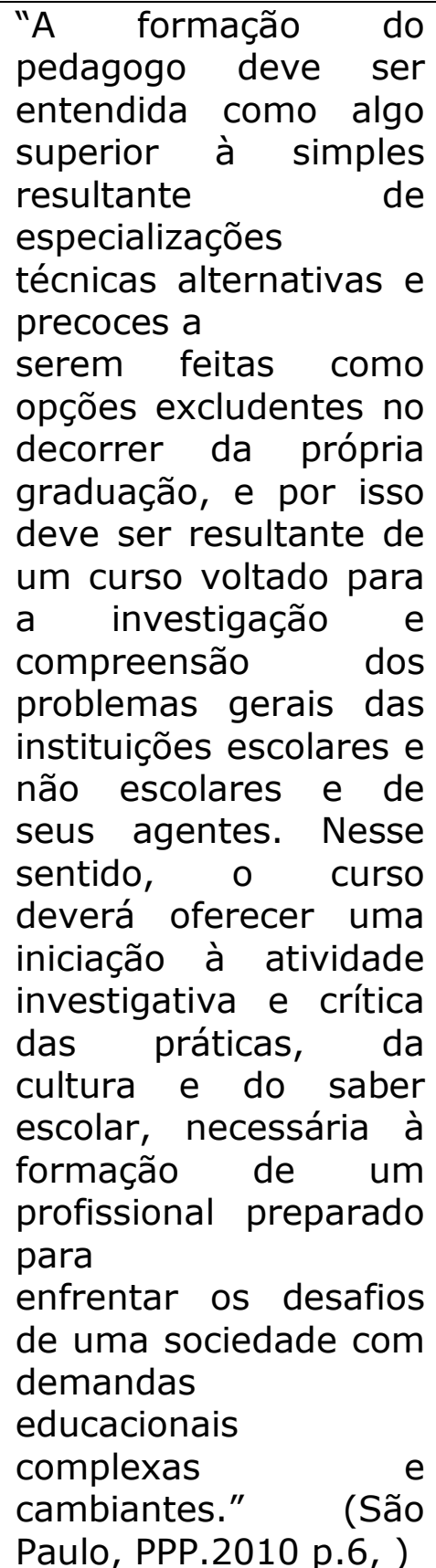 & 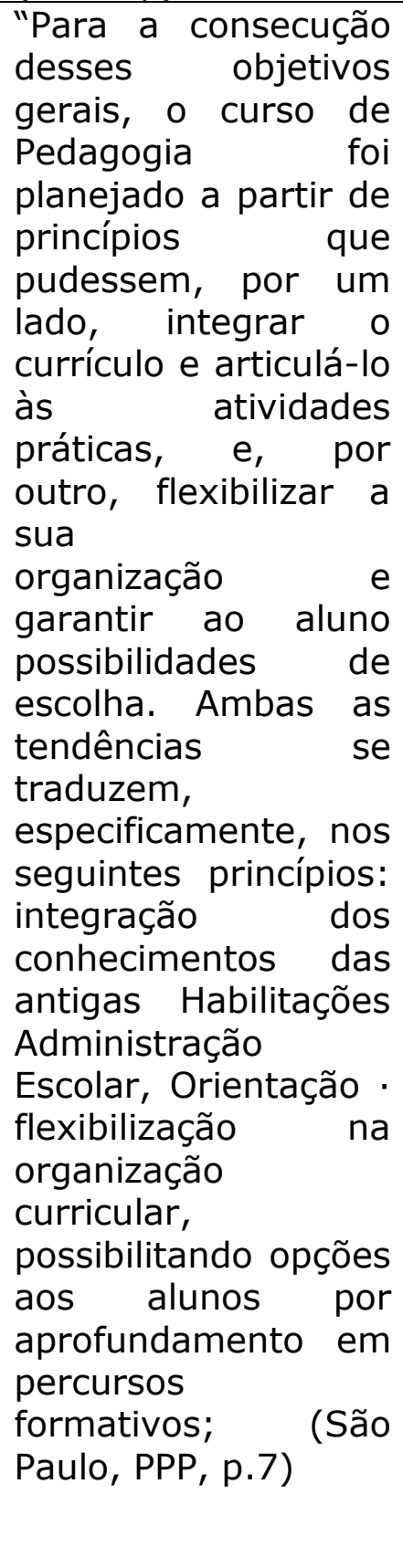 & $\begin{array}{l}\text { Na listagem } \\
\text { de disciplinas } \\
\text { eletivas e } \\
\text { obrigatórias } \\
\text { não } \\
\text { apresenta } \\
\text { nenhuma } \\
\text { disciplina } \\
\text { sobre história } \\
\text { local. Isso } \\
\text { não significa } \\
\text { que não } \\
\text { poderá ser } \\
\text { abordada } \\
\text { dentro de } \\
\text { alguma área } \\
\text { ou } \\
\text { projeto por } \\
\text { extensão de } \\
\text { pesquisa. }\end{array}$ \\
\hline
\end{tabular}




\begin{tabular}{|c|c|c|c|}
\hline $\begin{array}{l}\text { Universidade } \\
\text { Federal de } \\
\text { Pernambuco - } \\
\text { UFPE Campus } \\
\text { Agreste }\end{array}$ & 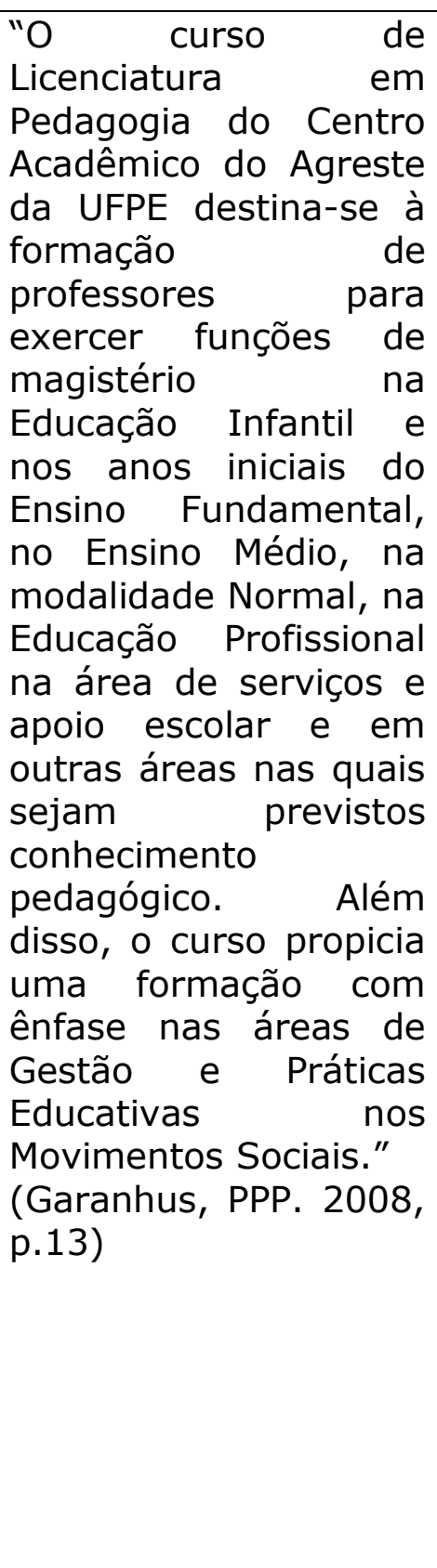 & $\begin{array}{l}\text { Desenvolver um } \\
\text { programa específico } \\
\text { de estudos teórico- } \\
\text { práticos, visando à } \\
\text { formação do } \\
\text { professor } \\
\text { oferecendo } \\
\text { fundamentos } \\
\text { didático-pedagógicos } \\
\text { próprios para a } \\
\text { prática educativa; } \\
\text { Oferecer um suporte } \\
\text { técnico-pedagógico } \\
\text { de das } \\
\text { acompanhamento, } \\
\text { de orientação e de } \\
\text { supervisão do dá } \\
\text { atividades de prática } \\
\text { de docência dos } \\
\text { futuros professores; } \\
\text { Desenvolver um } \\
\text { programa espećfico } \\
\text { de estudos teórico- } \\
\text { práticos, visando à } \\
\text { formação do gestor } \\
\text { educacional, } \\
\text { oferecendo } \\
\text { fundamentos } \\
\text { didático-pedagógicos } \\
\text { próprios para essa } \\
\text { prática; } \\
\text { (Garanhus, PPP. } \\
\text { p.14) }\end{array}$ & $\begin{array}{l}\text { Na listagem } \\
\text { de disciplinas } \\
\text { eletivas e } \\
\text { obrigatórias } \\
\text { não } \\
\text { apresenta } \\
\text { nenhuma } \\
\text { disciplina } \\
\text { sobre história } \\
\text { local. Isso } \\
\text { não significa } \\
\text { que não } \\
\text { poderá ser } \\
\text { abordada } \\
\text { dentro de } \\
\text { alguma área } \\
\text { ou por } \\
\text { projeto de } \\
\text { extensão } \\
\text { pesquisa. }\end{array}$ \\
\hline $\begin{array}{l}\text { Universidade } \\
\text { de Brasília - } \\
\text { UNB }^{4}\end{array}$ & $\begin{array}{l}\text { Permitir o contato dos } \\
\text { alunos com a realidade } \\
\text { do campo de trabalho. } \\
\text { Propiciar } \\
\text { formação ampla } \\
\text { (Distritor cultural. } \\
\text { PPP.2012, p23). }\end{array}$ & $\begin{array}{l}\text { Formar profissionais } \\
\text { conscientes de sua } \\
\text { historicidade } \\
\text { comprometidos com } \\
\text { os anseios de outros } \\
\text { sujeitos, individuais } \\
\text { e coletivos, } \\
\text { socialmente } \\
\text { referenciados para } \\
\text { formular, } \\
\text { acompanhar }\end{array}$ & $\begin{array}{ll}\text { Não } & \text { foi } \\
\text { possível } & \text { ter } \\
\text { acesso } & \text { as } \\
\text { disciplinas. }\end{array}$ \\
\hline
\end{tabular}

${ }^{4}$ Projeto Político do Curso de Pedagogia à distância versão preliminar. 


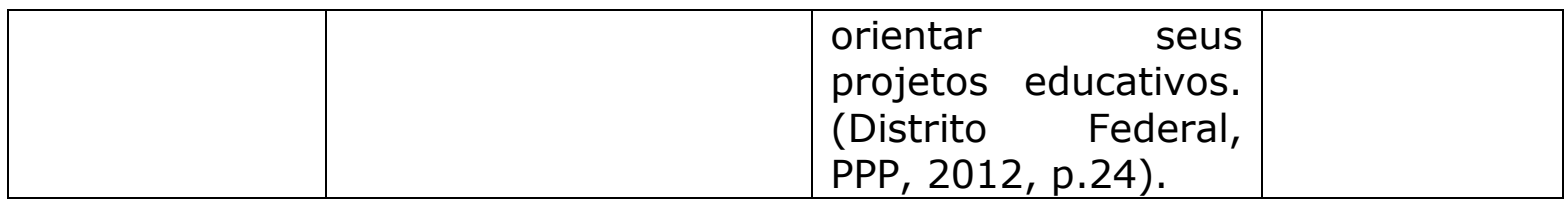

Fonte: quadro produzido pelas autoras

O fato de pouca visibilidade da história local na formação de professores pode relacionar-se ao pouco espaço na academia para o ensino de História enquanto campo de pesquisa e de conhecimento. Em contrapartida, verificamos tanto nos objetivos estabelecidos como na finalidade dos cursos analisados a ênfase dada a crítica a complexidade do mundo contemporânea e a compreensão dos problemas cotidianos, a ênfase a cultura e o contato com a realidade como elementos fundantes da formação. A flexibilidade, a interdisciplinaridade e a relação teoria e prática parecem ser outras características dos Projetos Políticos Pedagógicos do Curso de Pedagogia na contemporaneidade.

Pelos dados alocados acima parece que estudar a história e a educação da comunidade não é um elemento essencial na formação do/a pedagogo/a, apesar desse profissional ter que intervir em diferentes realidades da comunidade a qual encontra-se inserido. $O$ ensino da história local deve ser pensado como espaçotempo de fronteiras e de negociação das identidades ampliando a possibilidades de compreensão do mundo da vida ${ }^{5}$ (MONTEIRO; PENNA, 2011).

A partir dessa linha de raciocínio entendemos que o estudo sobre a História e a educação local parece ser um elemento chave para que o educador possa compreender melhor a realidade que está imerso. E isso implica ir ao encontro das representações construídas no meio local, a cultura produzida, aos problemas vividos e os desafios a serem enfrentados ao longo da história.

\footnotetext{
${ }^{5}$ Estamos utilizando uma expressão de Habermas.
} 


\section{A disciplina Tópicos de História da Educação em Alagoas: itinerários, histórias e desafios}

Compreendemos que a formação de professoras e professores apresentase como espaço privilegiado de desconstrução de muitos conhecimentos adquirido ao longo do tempo de escolarização. Há necessidade de questionamento das tradições, daquilo que foi estabelecido como certo e como verdade absoluta.

Foi com o intuito de romper com certas tradições que a disciplina eletiva no curso de Pedagogia intitulada Tópicos de História da Educação em Alagoas foi organizada. O desafio começou quando olhamos para a ementa da disciplina e sua carga horária. Em outras palavras, a sua amplitude não correspondia com as horas destinadas para estudo com os estudantes. Além disso, as eletivas no curso de Pedagogia da UFAL somente podem ser cursadas a partir do quarto período recebendo estudantes dos diferentes semestres. Nesse sentido, tínhamos educandos (as) do quarto ao sétimo período com interesses e desejos diferentes. Abaixo apresentamos um quadro com a ementa da disciplina.

\section{Quadro 2- Ementa da disciplina - Tópicos de História da Educação em Alagoas}

\begin{tabular}{|l|l|}
\hline Disciplina & TÓPICOS DE HISTÓRIA DA EDUCAÇÃO EM \\
& ALAGOAS- Ano: 2012.1 - Carga horária 40 horas \\
\hline Ementa & $\begin{array}{l}\text { Estudos sobre a trajetória da educação em Alagoas, do } \\
\text { Império à República com enfoque nas políticas públicas, }\end{array}$ \\
& na legislação educacional, nas ideias e teorias \\
& pedagógicas (e na expressão dessas através dos \\
& recursos didáticos: obras didáticas e métodos de \\
& ensino), na biografia de educadores alagoanos, nas \\
& instituições educacionais públicas, particulares e \\
& filantrópicas e na educação superior. \\
\hline
\end{tabular}

Fonte: Projeto Político Pedagógico do curso de Pedagogia da UFAL, 2006.

Pela ementa da disciplina tínhamos um desafio enorme pelo tempo cronológico estabelecido. Estudar a educação alagoana do Império a República é um desafio grande no intervalo de tempo pequeno destinado a disciplina. A pergunta lançada era: como desenvolver o curso dentro do contexto proposto, oferecendo subsídio para ampliar o conhecimento e desenvolver o gosto pela 
história? É evidente que fizemos recortes, que fomos constituindo as discussões a partir também do nosso campo de pesquisa. O nosso olhar teve como a amplitude as questões educacionais, sociais, políticas, econômicas e as contradições existentes nas comunidades estudadas. Fizemos a opção de trabalhar principalmente a história dos excluídos. Segue uma síntese em forma de quadro os textos estudados.

Quadro 3 - Sínteses dos textos trabalhados na Eletiva - Tópicos de História da Educação em Alagoas

\begin{tabular}{|c|c|c|}
\hline TEXTOS & AUTORES & ANO \\
\hline $\begin{array}{l}\text { Folclorização e } \text { Significado } \\
\text { Cultural do Negro }\end{array}$ & Zezito de Araújo & $S / d^{6}$ \\
\hline $\begin{array}{l}\text { Maceió, cidade negra } \\
\text { diversidade e espacialidade } \\
\text { de manifestações, bens e } \\
\text { serviços afro-brasileiros }\end{array}$ & $\begin{array}{l}\text { Bruno César Cavalcanti } \\
\text { Rachel } \\
\text { Rocha de Almeida Barros }\end{array}$ & S/d \\
\hline $\begin{array}{l}\text { De como se constituiu a vida } \\
\text { social em terras alagoanas }\end{array}$ & Elcio de Gusmão Verçosa ${ }^{7}$ & 2006 \\
\hline $\begin{array}{l}\text { Com a República chegará } \\
\text { alguma modernidade } \\
\text { finalmente às Alagoas }\end{array}$ & Elcio de Gusmão Verçosa & 2006 \\
\hline $\begin{array}{l}\text { Lembranças de } \quad \text { Antônio } \\
\text { Selestino, Pajé Xucuru-Kariri }\end{array}$ & $\begin{array}{c}\text { Rogério Rodrigues dos } \\
\text { Santos } \\
\text { Gilberto Geraldo }\end{array}$ & 2011 \\
\hline $\begin{array}{l}\text { Breve esboço sobre o lugar } \\
\text { da Escola para os Povos } \\
\text { Indígenas no Brasil }\end{array}$ & $\begin{array}{l}\text { José Ivamilson Silva } \\
\text { Barbalho }\end{array}$ & 2011 \\
\hline $\begin{array}{l}\text { A História de Maceió para } \\
\text { crianças }\end{array}$ & $\begin{array}{l}\text { Leda Maria de Almeida } \\
\text { Sandra Lúcia dos Santos } \\
\text { Lira }\end{array}$ & 2000 \\
\hline $\begin{array}{l}\text { Quilombos no Brasil e } \\
\text { singularidade de Palmares }\end{array}$ & Maria de Lourdes Siqueira & $\mathrm{S} / \mathrm{d}$ \\
\hline Saberes, $\quad$ descobertas, & Clara Suassuna Fernandes & $\mathrm{S} / \mathrm{d}$ \\
\hline
\end{tabular}

${ }^{6}$ Os textos que estão sem dada foi retirado da internet e faz parte da coleção Kulé Kulé.

7 Cf. VERÇOSA, Élcio de Gusmão. Cultura e educação nas Alagoas: história, histórias. 4.ed. Maceió: EDUFAL, 2006. 


\begin{tabular}{|c|c|c|}
\hline 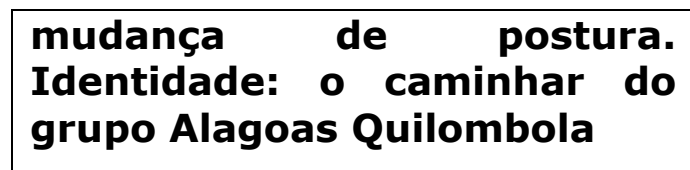 & & \multirow[b]{2}{*}{$\mathrm{S} / \mathrm{d}$} \\
\hline $\begin{array}{l}\text { Quilombo Muquém, uma } \\
\text { comunidade visível? }\end{array}$ & Clara Suassuna Fernandes & \\
\hline $\begin{array}{llr}\text { Conceição } & \text { dos Caetanos: } \\
\text { Cultura } & \text { Quilombola no } \\
\text { interior cearense } & \end{array}$ & $\begin{array}{c}\text { Maria Cecília Felix Calaça } \\
\text { Reginaldo Ferreira } \\
\text { Domingos } \\
\text { Henrique Cunha Júnior }\end{array}$ & 2011 \\
\hline $\begin{array}{l}\text { Historiografia Quilombolas } \\
\text { em Regiões do Ceará }\end{array}$ & Simone Dantas & 2011 \\
\hline Movimentos negros no Brasil & Roseane Maria de Amorim & 2011 \\
\hline O canto nas escolas & Craveiro Costa $^{8}$ & 2011 \\
\hline Ensino de História da Pátria & Craveiro Costa & 2011 \\
\hline Educação Cívica & Craveiro Costa & 2011 \\
\hline Domingos Moeda & Craveiro Costa & 2011 \\
\hline A escola rural & Craveiro Costa & 2011 \\
\hline A proclamação & Craveiro Costa & 2011 \\
\hline $\begin{array}{l}\text { A terra arável Plano de Aula } \\
\text { das escolas }\end{array}$ & Craveiro Costa & 2011 \\
\hline A escola moderna & Craveiro Costa & 2011 \\
\hline Diegues Junior & Craveiro Costa & 2011 \\
\hline $\begin{array}{l}\text { A evolução intelectual de } \\
\text { Alagoas }\end{array}$ & Craveiro Costa & 2011 \\
\hline A escola isolada & Craveiro Costa & 2011 \\
\hline Deve a professora casar? & Craveiro Costa & 2011 \\
\hline
\end{tabular}

Fonte: Quadro produzido pelas autoras.

No geral procuramos priorizar os autores alagoanos, mas sempre fazendo a relação com os autores e discussões em âmbito nacional e regional. Os textos deveriam ser lidos, debatidos, questionados a partir da nossa realidade e dos nossos problemas cotidianos.

${ }^{8}$ Cf. VERÇOSA, Elcio de Gusmão; MADEIRA, Maria das Graças de Loiola (Coordenadores). COSTA, Craveiro. Instrução pública e instituições culturais de Alagoas e outros ensaios. Maceió: EDUFAL, 2011. 
No decorrer da disciplina realizamos também estudo de campo com o intuito de aprendermos de forma mais aprofundada a nossa história. Temos uma riqueza arquitetônica, uma pluralidade de histórias que nem sempre valorizamos e conhecemos. Foi nessa perspectiva que propomos um estudo de campo em alguns espaços alagoanos.

Quadro 4 - Lugares da aula de campo

\begin{tabular}{|l|l|}
\hline LUGARES & DATA - OBJETIVOS \\
\hline Museu Theo Brandão & $\begin{array}{l}27 / 03 / 2012 \text { - Conhecer a riqueza do } \\
\text { folclore alagoano e sua importância } \\
\text { para a construção da identidade dos } \\
\text { estudantes. }\end{array}$ \\
\hline Cidade de Penedo & $\begin{array}{l}24 / 04 / 2012 \text { - Analisar o barroco } \\
\text { alagoano e compará-lo com outros } \\
\text { espaços da federação. }\end{array}$ \\
\hline Serra da Barriga & $\begin{array}{l}15 / 05 / 2012 \text { - Analisar a cultura } \\
\text { afrobrasileiro e as formas de } \\
\text { resistências dos negros e negras no } \\
\text { nosso país. } \\
\text { - Conhecer o memorial Serra da } \\
\text { Barriga e sua importância para a } \\
\text { preservação da cultura negra. }\end{array}$ \\
\hline
\end{tabular}

O estudo do meio ou estudo de campo possibilita concretizar interpretações interdisciplinares e levantamento de questões que o trabalho por meio de textos escritos e por imagens nem sempre é possível. Isso acontece devido o contato com pessoas, com espaços e situações diferentes do ambiente escolar. É uma oportunidade de dialogar com pessoas, observar concretamente determinada situação e atentar para fatos cotidianos que nem sempre estamos atentos (BITTENCOURT, 2004).

Esse método de investigação exige planejamento, estudo prévio do local, organização de roteiro a ser seguido, preparação do caderno de campo. Enfim, não deixa de ser o momento de tensão para os docentes que estão sempre atarefados e com acúmulo de trabalho. Entretanto, é um momento de aprendizagem que vale a pena, pois temos a possibilidade de realizar a pesquisa in lócus. 
No nosso caso, a forma de registro foi a produção de vídeos ${ }^{9}$ apresentando a experiência do grupo. Após o estudo de campo realizava-se na sala de análise debates, retomadas dos textos e reflexões sobre o que foi vivenciado.

Para finalizar a disciplina combinamos que os estudantes deveriam fazer estudos de alguns bairros e apresentá-los por meio de vídeos, destacado algumas questões históricas, anseios da comunidade e memórias de pessoas idosas caso fosse possível. Seguem os nomes dos bairros estudados com breve descrição do trabalho realizado.

Quadro 5 - Estudos dos bairros ${ }^{10}$ de Maceió apresentados em vídeos

\begin{tabular}{|c|c|}
\hline BAIRROS & DESCRIÇÃO DAS ATIVIDADES \\
\hline RIACHO DOCE & $\begin{array}{c}\text { Foi apresentado um slide contendo a } \\
\text { história do bairro com um vídeo e } \\
\text { depoimento de uma idosa sobre o } \\
\text { lugar. }\end{array}$ \\
\hline FERNÃO VELHO & $\begin{array}{l}\text { Foi apresentado um slide contendo a } \\
\text { história do bairro com um vídeo. }\end{array}$ \\
\hline CENTRO & $\begin{array}{l}\text { Foi apresentado um slide contendo a } \\
\text { história do bairro com um vídeo. }\end{array}$ \\
\hline $\begin{array}{l}\text { BARRA NOVA (MARECHAL } \\
\text { DEODORO) }\end{array}$ & $\begin{array}{l}\text { Foi apresentado um slide contendo a } \\
\text { história do bairro com um vídeo e } \\
\text { depoimento de uma idosa sobre o } \\
\text { lugar. }\end{array}$ \\
\hline JACINTINHO & $\begin{array}{l}\text { Foi apresentado um slide abordando } \\
\text { a temática. }\end{array}$ \\
\hline JARAGUÁ & Foi apresentado um \\
\hline GARÇA TORTA & $\begin{array}{l}\text { Foi apresentado um slide abordando } \\
\text { a temática. }\end{array}$ \\
\hline SANTA LÚCIA & $\begin{array}{l}\text { Foi apresentado um slide abordando } \\
\text { a temática. }\end{array}$ \\
\hline BEBEDOURO & $\begin{array}{l}\text { Foi apresentado um slide abordando } \\
\text { a temática. }\end{array}$ \\
\hline CHÃ DE BEBEDOURO & $\begin{array}{l}\text { Foi apresentado um slide contendo a } \\
\text { história do bairro com um vídeo. }\end{array}$ \\
\hline
\end{tabular}

${ }^{9}$ Escolhíamos algumas pessoas do grupo para fazer o registro em forma de vídeo.

10 Para maiores conhecimentos acerca dos bairros apresentados, visitar o sítio: http://www.bairrosdemaceio.net/site/index.php?Canal=Bairros 
O estudo do bairro foi um momento muito rico em que os estudantes pesquisavam sobre os lugares em diferentes fontes. Alguns fizerem entrevistas com idosos, trouxeram questões e figuras (pessoas conhecidas) do cotidiano. Esse debate foi muito importante na medida em que geraram comentários sobre os lugares, discussões entre o passado e o presente e questionamentos sobre coisas não pensadas em outros momentos. Uma estudante comentou que:

Todos os aspectos estudados foram importantes para o aprendizado. Os estudos dos bairros, da cultura afro e indígenas foram fundantes para desconstruir alguns estereótipos aprendidos aos longos dos anos de escolarização. (Estudante E 70 período).

Com o intuito de avaliar o trabalho da disciplina e os resultados alcançados solicitamos ao grupo de estudantes que destacassem pelo menos dois aspectos importantes no ensino da história local. Em relação a essa questão foi afirmado o seguinte:

Adquirimos conhecimentos sobre aspectos sociais, culturais, políticos educacionais de nossa história local; Tomamos conhecimento de nossos antepassados. (Estudante A $5^{\circ}$ período)

Ajuda na construção das identidades. Seja a identidade com o a sua localidade ou a identidade entico racial. Favorece o estudo das memórias e histórias de pessoas que estão vivas e que têm muito para contar. (Estudante B 70 período)

Entendemos que a construção da nossa identidade se dá pelo processo de interação com os nossos pares, com os olhares e vivências dos diversos grupos, confrontando com aquilo que pensamos sobre o que somos. O olhar para os sujeitos que têm histórias diferentes da nossa, mas que ao mesmo tempo comunga de coisas parecidas permite muitos questionamentos e possibilidades de rever pontos de vistas, consolida outros, e ainda abri espaço para o processo de novos conhecimentos. Entretanto, não deixa de ser um processo conflituoso.

A polifonia presente no palco identitário comparece evidentemente à escola. Nesse momento, especialmente, explicitam-se receios de alguns professores para a adesão acrítica a plataforma de identidades rígidas, com vislumbre dos riscos de transformação do ensino de história, sobretudo, em exercício de conformação identitária que impeça a liberdade de adesão a registros identitários diversos (PEREIRA, 2011, p. 161). 
Pelo que foi exposto acima, trabalhar com as diferentes identidades não é algo fácil, exige muito esforço do docente além de ser um desafio constante. Para Hall (2003, p.13) "a identidade plenamente unificada, completa, segura e coerente é uma fantasia." Daí que, somos confrontados diariamente por multiplicidades de formas de ser e pensar o mundo.

Grosso modo, podemos afirmar que a nossa preocupação foi oferecer aos educandos e educandas o conhecimento sobre as histórias que não foram contadas ao longo da nossa escolarização e as implicações da nossa prática para a formação de pessoas comprometidas com uma sociedade mais justa. De outra parte tivemos a preocupação em oferecer subsídios para que estes estudantes/professores (as) possam se comprometer com novas pesquisas e que aprofundem o conhecimento adquirido na disciplina.

\section{Apontamentos (in)conclusivos}

A formação dos profissionais na atualidade tem exigido um conjunto de saberes que vão além da relação teoria e prática. Quanto ao seu alcance compreendemos que a formação interdisciplinar exige um ensino que tenha uma preocupação com os estudos da cultura local em consonância com a realidade nacional conforme são salientados nos Projetos Políticos Pedagógicos do curso de Pedagogia analisados.

Quanto ao ensino de história na escola e na universidade sabemos que precisam ser ressignificados para atender a demanda do mundo contemporâneo. Por outro lado, esse ensino não pode está desvinculado de uma formação teórica sólida e consistente.

Assim, terminamos provisoriamente esse texto com ainda muitas questões. E mesmo não tendo resposta, formulamos como convite para ser pensado e dialogado em outros espaços. O estudo da história local deveria fazer parte dos currículos de todas as licenciaturas voltadas para as Ciências Humanas? Quais as possibilidades de se trabalhar a História dentro de uma sociedade que vive cultuando o presente e esquece o passado? E ainda: como tornar o passado significativo para as crianças, jovens e adultos da atualidade? 
Enfim, muitas outras questões podem ser levantadas e para se promover novos diálogos.

\section{Referências}

AMORIM, R. M. As implicações dos parâmetros curriculares nacionais para a prática pedagógica dos professores de História do ensino fundamental da rede municipal do Jaboatão dos Guararapes. 250f. Dissertação (Mestrado em Educação) - Programa de Pós-Graduação em Educação, Universidade Federal de Pernambuco, Recife, 2004.

As Práticas Curriculares Cotidianas: um Estudo da Educação das Relações Étnico-Raciais na Rede Municipal de Ensino do Recife. 2011. Tese (Doutorado em Educação) - Programa de Pós-Graduação em Educação, Universidade Federal de Pernambuco, Recife, 2011.

ALBUQUERQUE JUNIOR, D. M. de. História: a arte de inventar o passado. São Paulo: Edusc 2007.

BITTENCOURT, C. M. F. Ensino de História: fundamentos e métodos. São Paulo: Cortez, 2004. (Coleção Docência e Formação).

BRASÍlIA. Projeto Político Pedagógico do curso de Pedagogia. Versão Preliminar. Brasília, UNB, 2012.

CARRETERO, M. Construir e ensinar as Ciências Sociais e História. Porto Alegre: Artes Médicas, 1997.

CARUARU. Projeto Político Pedagógico do curso de Pedagogia. UFPE, Caruaru Pernambuco, 2008.

FONSECA, T. N. L. Exaltar a pátria ou formar o cidadão. In: . História \& ensino de História. 2. ed. Belo Horizonte: Autêntica, 2004.

HALL, S. A identidade cultural na pós-modernidade. Tradução de Tomaz Tadeu da silva, Rio de Janeiro: DP\&A, 2003.

MONTEIRO, A. M. F. da C.; PENNA, F. de A. Ensino de História: saberes em lugar de fronteiras. Revista Educação e Realidade, Porto Alegre, v. 36, n.1, p.191-211, jan./abr., 2011.

OLIVEIRA, M. M. D. de. O ensino de história, a memória e o patrimônio cultural. História \& Ensino, Londrina, v. 15, p. 119-130 ago. 2009.

PAIM, E. A.; CORREA, J. O. O ensino de História Regional nos anos iniciais da educação básica. História \& Ensino, Londrina, v. 15, p. 23-38. 2009.

PEREIRA, J. S. Diálogos sobre o exercício da docência. Recepção das Leis 10.639/2003 e 11.645/08. Revista Educação e Realidade, Porto Alegre, v. 36, n.1 p.147-172, jan./abr., 2011.

PESAVENTO, S. J. História \& História cultural. Belo Horizonte: Autêntica, 2003.

PIAUÍ. Projeto Político Pedagógico do curso de Pedagogia. Teresina, s/d.

RECIFE. Projeto Político Pedagógico do Curso de Pedagogia. Recife, UFPE, 2007. 
ROCHA, U. História, currículo e cotidiano escolar. São Paulo: Cortez, 2002. SAMARA, E. de M.; TUPY; I. S. S. T. História \& documentos e metodologia de pesquisa. Belo Horizonte: Autêntica, 2010.

SÃo PAULO. Projeto Político Pedagógico do curso de Pedagogia. São Paulo: USP, 2010.

SCHMIDT, M. A.; CAINELLI, M. Ensinar História. São Paulo: Scipione, 2004. (Coleção Pensamento e ação no magistério).

VERÇOSA, E. de G.; MADEIRA, M. das G. de L. (Coord.). COSTA, C. Instrução pública e instituições culturais de Alagoas e outros ensaios. Maceió: EDUFAL, 2011.

Recebido em 09 de março de 2013.

Aprovado em 04 de agosto de 2013. 